\title{
O HOMEM VAZIO: UMA CRÍTICA AO UTILITARISMO ${ }^{1}$
}

\author{
Érico Andrade
}

\begin{abstract}
RESUMO: O objetivo do meu artigo é criticar a compreensão utilitarista do agente moral como átomo racional que está disposto invariavelmente a agir de acordo com o não sofrimento. Minha hipótese é a de que o utilitarismo esvazia os seres humanos de suas motivaçóes para oferecer uma imagem opaca do agente moral. Por isso, ele é incapaz de solucionar dilemas morais que envolvem, por um lado, o autossacrifício por razóes afetivas e, por outro, conflitos que opóem culturas distintas. Meu ponto é que não é necessariamente imoral a ação de um agente o qual sacrifica a solução ótima (proposta pelo cálculo utilitário e que privilegia a maioria), em nome de uma motivação afetiva, que julga que uma vida pode valer mais do que outra, nem o sofrimento é necessariamente imoral em todas as culturas de modo uniforme.
\end{abstract}

PALAVRAS-CHAVE: Moral. Utilitarismo. Bem. Contexto. Empatia.

\section{INTRODUÇÃo}

Considerando que, para uma teoria utilitarista, a felicidade consiste na satisfação dos interesses dos agentes morais ou simplesmente na rejeição do sofrimento por parte desses agentes, meu objetivo neste artigo será mostrar que o utilitarismo precisa de uma compreensão do bem que seja mais complexa e que não se encerre apenas na procura pela felicidade. Defenderei que essa compreensão mais complexa é fundamental para a adoção do cálculo de utilidade. Entre os utilitaristas, há uma tendência a levar em conta que a felicidade não contém em sua extensão os afetos no que concerne, pelo menos, à predicação da moralidade de uma ação. Acredito que essa tendência é a marca da falta de uma compreensão mais ampla das diversas motivações para as ações humanas. Nesse sentido, a minha crítica se concentra na visão austera

\footnotetext{
${ }^{1}$ Agradeço a todos os comentários feitos a algumas das versôes deste artigo, quando da sua apresentação em forma de palestra na UNICAMP e na UFSM, comentários esses importantes para eu precisar alguns pontos do texto.

${ }^{2}$ Doutor em Filosofia pela Sorbonne (Paris IV) - Professor da Universidade Federal de Pernambuco/ Centro de Filosofia e Ciências Humanas. Depto. de Filosofia. E-mail: ericoandrade@hotmail.com
} 
do utilitarismo quanto ao que pode ser tomado como critério para a avaliação de uma ação.

Minha hipótese é a de que o utilitarismo parte de uma tese razoável, a saber, a de que os agentes morais têm em princípio o mesmo valor - nas palavras de Bentham: "[...] todos devem contar por um, ninguém por mais de um" (BENTHAM apud MILL, 1861) - para concluir, de forma equivocada, que essa igualdade de valor se mantém a posteriori em qualquer contexto e assume a forma de uma constante para o cálculo racional. Ou seja, o fato de que todos os agentes morais podem, em princípio, ter um mesmo valor moral náo implica que, seja qual for o contexto ou a situação, os agentes morais são todos iguais, pois é perfeitamente possível que um agente moral sacrifique a solução ótima (proposta pelo cálculo utilitário e que privilegia a felicidade maioria) em nome de uma motivação afetiva, a qual potencializa, num determinado contexto, o valor de um agente moral em detrimento de outros.

Diferentemente de várias objeções clássicas ao utilitarismo, mapeadas muito bem por Cláudio Costa (2002), meu ponto é que a compreensão da felicidade só pode ocorrer no interior de um contexto no qual se determina a motivação da ação e os valores sociais (instituídos no horizonte do tempo) que lhe são agregados. Minhas objeçôes, portanto, não questionam o fato de que a felicidade (bem-estar) pode ser um dos nossos bens morais relevantes, mas meu ponto é que ela não é o único bem, nem se apresenta historicamente de maneira uniforme. Assim, parece-me que o utilitarismo elide uma discussão mais ampla sobre a natureza da felicidade e sobre as razóes que movem a ação humana, o que o torna pouco eficiente no que concerne à resoluçáo de alguns dilemas morais.

Para realizar a crítica proposta aqui, estruturarei meu artigo em três etapas. Primeiro, farei breves considerações sobre o que quero designar com o termo utilitarismo. Estou ciente, contudo, de que não há consenso quanto ao emprego desse termo e que certamente as minhas críticas podem não tocar alguns matizes do utilitarismo. Com efeito, as minhas objeçôes se dirigem mais particularmente à posição utilitarista de Cláudio Costa. O autor supramencionado é um dos raros filósofos no Brasil a apresentar uma defesa clara do utilitarismo e é um potencial interlocutor deste artigo. Se as minhas críticas apresentarem boas questóes contra sua posição, julgo que meu artigo terá obtido êxito em parte considerável de seu intento. Em seguida, tecerei algumas consideraçóes sobre a motivação das açóes individuais, no que chamo de discussão antropológica. Essa discussão visa a mostrar que a compreensão 
utilitarista do homem como uma espécie de átomo de prazer homogeneíza equivocadamente as motivaçóes humanas, à medida que estabelece uma hierarquia - questionável - entre os diferentes sentimentos humanos e que geralmente destina um papel pouco relevante para a empatia, no que diz respeito à predicação da moralidade ${ }^{3}$. Nesse caso, o utilitarismo tem um déficit antropológico, por desconsiderar que o altruísmo (por razóes neurológicas e afetivas) pode ser tomado como um valor moral que legitima o autossacrifício ou que justifica uma açáo dissonante da procura pela própria felicidade. No terceiro e último momento do meu artigo, farei uma crítica, chamada por mim sociológica, por meio da qual defenderei que o utilitarismo tem um importante déficit cultural, visto que, para a resolução de conflitos interculturais, é necessário reconhecer a diversidade de valores culturais. Ela, no entanto, é negligenciada pelo utilitarismo, na medida em que este homogeneíza as culturas por meio do apelo à felicidade da maioria. O "truque" do utilitarista é promover a desvinculação entre o indivíduo (cuja racionalidade seria uma marca constituinte independente da história) e a cultura (cuja variação não moldaria o desejo do indivíduo pela felicidade). Essa desvinculação permite ao utilitarismo tratar agentes morais de diferentes culturas de modo uniforme, como se todos os agentes devessem ter uma mesma compreensão da felicidade, mas o afasta da resolução de conflitos entre culturas, porque subordinada a compreensão da cultura a um agente moral desinteressado e, portanto, não põe em debate a função da cultura na determinação da moralidade. Concluirei que falta ao utilitarismo, por um lado, uma visão menos austera do agente moral e, por outro, um senso sociológico mais acurado.

\section{BREVES NOTAS SOBRE O UTILITARISMO}

Eu compreendo por utilitarismo, em termos éticos, a teoria moral que defende a otimização da felicidade (bem-estar) em detrimento do sofrimento.

\footnotetext{
${ }^{3}$ Tenho plena consciência de que Mill tece algumas críticas ao utilitarismo proposto por Bentham que se remetem ao questionamento do aspecto austero da compreensáo antropológica do ser humano aventada por aquele autor. Ainda que Mill reconheça o papel das emoçôes, ele ainda se mantém no registro de que o utilitarismo, em última análise, não introduz nos seus princípios básicos as emoçóes como critério de avaliação da ação moral. M. C. M. Dias defende, em função de uma análise estrutural e genética, que Mill assume um novo posicionamento quanto ao papel das emoçóes na moralidade, após seu problema mental. Ela se apoia, sobretudo, na Autobiografia de Mill, que efetivamente confessa sua crítica ao utilitarismo que se coloca indiferente às emoçôes (DIAS, 2011, p. 72-73). O ponto central da autora consiste na defesa de que a antropologia de Mill é diferente daquela sustentada por Bentham, o que desembocaria em visôes, em certa medida, dissonantes do utilitarismo. Segundo Dias, alguns defendem que o utilitarismo de Mill é anômalo.
} 
Não gostaria de sublinhar com essa definição apenas o utilitarismo clássico de matiz hedonista, pois acredito que ela é capaz de abarcar variaçóes mais sofisticadas do hedonismo que ainda trabalham no registro de que o ponto essencial de uma teoria utilitária repousa na promoção otimizada da felicidade ${ }^{4}$. Dessa forma, se entre duas alternativas há uma que promove a maior felicidade, esta deve ser a alternativa que o agente moral deve seguir (essa definição é próxima da produzida por SINGER, 2009, p. 11). Nesse sentido, o utilitarismo náo é, segundo Mill, "[...] a maior soma da felicidade do próprio agente, mas a maior soma da felicidade conjunta” (MILL, 1861, p. 196). O utilitarismo pensa a ação moral em função das consequências dessa ação para a felicidade de um conjunto o maior possível de pessoas (ver, por exemplo: SMART, 1956, p. 354). Essa posição subsidia efetivamente um cálculo para aferir em que medida uma ação teve ou não uma consequência boa, pois a variável é a quantidade de pessoas beneficiadas. $\mathrm{O}$ mapeamento empírico das possíveis consequências da ação torna exequível o cálculo que determina o maior número de beneficiados. Tenho consciência, contudo, de que não há consenso entre os utilitaristas quanto à natureza da felicidade ou do bem-estar, porém, várias definiçóes da felicidade tendem a assumir uma das diferentes matizes do hedonismo.

Se a felicidade é o bem moral para o qual tendem as nossas ações individuais, de um ponto de vista social as açóes devem estender a felicidade para um maior número possível de pessoas. Isto é, os indivíduos devem procurar a maximização da felicidade e a sociedade deve estender o máximo os benefícios entre os indivíduos, de modo a contemplar um número maior de indivíduos. Assim, o componente social obriga que as decisóes individuais sejam sintonizadas com o desejo da maioria. O utilitarismo defende que se deve inserir o interesse dos outros nos meus interesses 5 . Por isso, não me parece

\footnotetext{
${ }^{4}$ Mill é responsável por uma classificação dos prazeres, mas não deixa de assumir o binômio prazer e sofrimento como o principal vetor do utilitarismo (MILL, Utilitarismo, Cap. II). Sobre a qualificação do prazer em Mill, ver: SIMÓES , 2009, p. 48.

${ }^{5}$ A ideia de que a ação do indivíduo deve ser compatível com os interesses dos demais torna possível, segundo Hare, uma aproximaçáo parcial com o imperativo categórico de Kant, mais precisamente nas formulaçōes que prescrevem deveres para com os outros (HARE, 1998 p. 212). Sobre a crítica da assimilação da filosofia kantiana como um utilitarismo bastante, por assim dizer, mitigado, ver DALL'AGNOL, 2001. Dall'Agnol insiste, entre outras coisas, em que a filosofia kantiana tem um princípio essencial que é incompatível com o utilitarismo, qual seja, o ser racional é um fim em si mesmo. Um dos seus argumentos centrais é que a filosofia kantiana prioriza o respeito à pessoa, em detrimento, eventualmente, de sua felicidade. Para o autor, nem Kant pode ser utilitarista, nem Hare pode ser kantiano.
} 
muito correto defender que o utilitarismo é uma teoria do egoísmo moral, em sentido estrito.

Nessa perspectiva, Cláudio Costa argumenta que uma formulação consistente da máxima utilitária ou do princípio da utilidade tem que levar em consideraçáo a ideia de contrato. Ele retoma uma das formulaçóes da referida máxima: "[...] a ação moralmente correta é a que segue uma regra cuja adoção produz um bem maior para a sociedade que adota o sistema de regras à qual ela pertence" (COSTA, 2002, p. 169). Esse princípio ou máxima utilitária precisa, seguindo a argumentação de Cláudio Costa, de um adendo para evitar a objeção ao utilitarismo de regras, que preconiza a necessidade de se transgredir algumas normas sociais que oprimem, em vários casos, a maioria. Assim, ele defende uma aplicação geral do princípio supracitado, mediante a sua coordenação com o princípio clássico do utilitarismo conforme o qual “[...] uma ação moralmente correta é a que produz maior prazer (bem) e/ou menor sofrimento (mal) para a maioria” (COSTA, 2002, p. 164).

O princípio da utilidade defende que cada ação particular (utilitarismo de atos) ou padrão de açôes (utilitarismo de regras) deve agregar e distribuir ao máximo a felicidade ou o bem-estar. As açóes são pensadas sempre no horizonte da otimização dos bens, que devem, sempre que possível, ser distribuídos de forma equitativa, uma vez que náo há no agente moral uma qualidade que possa diferenciá-los dos demais agentes. Isto é, a homogeneização do agente moral implica a extensão de um benefício a um maior número possível de agentes morais de modo razoavelmente uniforme. As vantagens da posição utilitarista no geral estão circunscritas, pelo menos, a dois pontos: A) ele parece estar de acordo com alguma de nossas intuiçóes básicas, quando oferece uma resposta razoável para certos dilemas morais. Por exemplo, considerando que haverá uma enchente após uma abertura imprescindível de uma barragem prestes a se romper, e que algumas pessoas precisam ser desalojadas, para que toda a cidade possa sobreviver por meio da construçáo de outra barragem, pode-se julgar razoável que algumas pessoas sejam desabrigadas para que as demais sobrevivam. B) O utilitarismo tem um comprometimento empírico interessante, na medida em que estabelece princípios morais que podem ser quantificáveis e testados, quanto à sua validade, na experiência. A atitude utilitária é exequível. Ainda que apresentadas de forma geral, essas razóes servem de indicativo da força do utilitarismo, que sempre está presente nos debates da ética contemporânea. 
A noção de bem-estar ou felicidade social é suficientemente ampla para abarcar a otimização do prazer em detrimento da dor, inscrita nos interesses individuais. De qualquer modo, o indivíduo é considerado como o agente moral que age em conformidade com seu próprio bem-estar ou felicidade. Contudo, por que a escolha da otimização da felicidade ou bem-estar deve governar a avaliação de cada ação, no que concerne ao uso dos predicados morais?

O epicentro da tese do utilitarismo é a aposta na igualdade do valor dos agentes morais, que compreende cada agente como um átomo que visa invariavelmente à realização dos seus desejos ligados, sobretudo, ao não sofrimento. Como os indivíduos têm um mesmo valor moral, as açóes são orquestradas pelo princípio que anula ações as quais se oponham à maioria, ao passo que "recompensa" as açóes que conseguem contemplar a maioria dos agentes morais. O reconhecimento da igualdade de valor dos agentes morais acarreta a construção de uma moral que avalia as açóes em virtude do maior benefício que ela pode trazer para uma quantidade maior de indivíduos. Contudo, permanece a questáo referente ao reconhecimento dos indivíduos do igual valor de cada agente moral. O que levaria os indivíduos a elegerem como principal valor moral a igualdade de valor de cada agente moral, independente do contexto? Essa igualdade está presente em qualquer contexto? Essa questão é essencial, porque toca na motivação do agente moral para procurar a felicidade ou o bem-estar, visto que é necessário reconhecer moralmente um valor para que ele possa ser o critério de avaliação da ação moral. Defenderei agora que o pressuposto de que cada indivíduo tem um mesmo valor moral, embora sedutor, falha em alguns casos por idealizar o agente moral, desconsiderando a potencial moralidade de açóes que envolvem, principalmente a empatia pelo outro e os afetos de modo geral.

\section{O DÉFICIT ANTROPOLÓGICO DO UTILITARISMO}

O utilitarismo pressupóe que os indivíduos são capazes de separar interesses difusos e investirem numa atitude racional, que planifica as suas escolhas e hierarquiza os seus prazeres em sintonia com a disponibilidade dos recursos escassos. Por isso, os indivíduos são tomados como átomos racionais que devem agir conforme uma determinação de um cálculo de otimização de recursos. Ainda que os indivíduos possam, em vários contextos, levar em consideraçáo o bem-estar da maioria - enquanto horizonte, porque nem sempre é viável fazer, como bem pontua Williams, o cálculo do bem-estar 
(WILLIAMS, 2005, p. 151-156) -, o ponto que quero ressaltar reside nos problemas de tomar a regra do cálculo utilitário como um critério para a avaliação das ações, independentemente do contexto afetivo no qual elas ocorrem. Dessa maneira, se, por um lado, o utilitarismo está de acordo com algumas de nossas intuiçóes, como no exemplo que ofereci da represa, por outro, ele se afasta de algumas outras intuiçóes que me parecem fundamentais. Destaco particularmente a empatia, não apenas como um elemento de motivação moral, mas como um dos critérios de avaliação moral.

Entendo por empatia toda disposiçáo para agir em sintonia com um grau de altruísmo que implica algum sacrifício do próprio interesse em nome de outra pessoa. Em situaçôes extremas, é possível que indivíduos façam alguns sacrifícios, náo propriamente em função da atitude mais racional (no sentido utilitarista), todavia, em função de um interesse difuso ou que não contribui necessariamente com a maioria. Será que seria possível dizer que, a priori, esse indivíduo não procedeu moralmente de forma correta?

Deixem-me oferecer um exemplo: numa casa que está sendo destruída pelas chamas, um pai tem a opção de fugir quase ileso e garantir certamente o bem-estar de três dos seus quatro filhos, que não estão na casa, ou ficar na casa, tentando resgatar o outro filho, mas com uma taxa pequena de chances de sobreviver. Não é necessário traçar um grande levantamento empírico para constatar que boa parte dos pais tomaria a decisão de tentar salvar o filho, ainda que isso significasse que os outros filhos ficariam, de algum modo, desassistidos. O ponto é que a decisão do pai não é racional (no sentido do utilitarismo), porém, é bastante compreensível do ponto de vista do vínculo afetivo que ele guarda com o seu filho. Não é a priori contraintuitivo tomar decisões que não se pautam num cálculo racional que otimiza o bem-estar. Elas podem ser bem intuitivas, como acredito que seja o hipotético caso mencionado, e podem eventualmente servir para a avaliação da ação moral. Nesse sentido, não se trata aqui do que Smart chama de "fraqueza de vontade" (SMART, 1978), pois não seria uma posição meramente particular que mostraria, supostamente, mais uma ação sintonizada com uma dificuldade de agir segundo o cálculo de utilidade do que uma ação recomendável moralmente. $\mathrm{O}$ ponto é que a empatia é uma das variáveis para a motivação moral, à proporção que também serve como um dos critérios para avaliar a ação. A ação de salvar o filho, conforme narrei aqui, é socialmente louvada e não se restringe a uma "fraqueza de vontade" individual. 
Não pretendo argumentar que a empatia é o único critério para a avaliação moral, mas apenas que ela não pode ser completamente excluída como critério moral. Não pretendo entrar na seara das discussôes de metaética sobre a força moral da empatia ou sobre em que medida ela é um sentimento moral imprescindível, mas acredito que é necessário que o utilitarismo justifique o critério da escolha do cálculo racional, sem desconsiderar as objeçôes apresentadas aqui referentes à presença dos sentimentos morais na avaliação da ação. Meu ponto é que o utilitarismo se compromete com uma rígida noção de indivíduo (átomo racional), a qual nem sempre está em sintonia com a pulverização de interesses que marca a ação moral e que torna os agentes morais um feixe de múltiplas motivaçóes.

Minha intenção, com o exemplo, consiste em mostrar que a quantidade de beneficiados não pode a priori ser condiçâo necessária e suficiente para avaliar moralmente uma ação. $\mathrm{O}$ utilitarismo se compromete com uma individuaçáo do agente moral que sedimenta apenas uma das feiçôes da ação humana, inscrita na racionalidade responsável pela maximização do bem-estar ou da felicidade. Ora, se não é natural ou absolutamente espontâneo que nossas açóes sejam pautadas apenas na maximização do bem-estar, é necessário avaliar até que ponto uma compreensão unívoca do bem-estar ou da felicidade pode ser um critério moral suficientemente abrangente. É necessário, portanto, que se ofereçam outras qualidades ao critério da quantidade de beneficiados, para que ele possa ser legitimado como tribunal de julgamento da ação moral. Em suma, é preciso qualificar o agente moral racional para avaliar, não se a sua conduta foi ou não a mais correta quanto à extensão dos beneficiados que ela abarca, mas se moralmente o referido benefício é um bem moral relevante. $\mathrm{O}$ critério da quantidade não é suficiente para justificar a adoçâo do cálculo de utilidade.

A questão que coloco aqui não versa apenas sobre a excessiva idealização do agente moral como um agente pronto para executar um cálculo racional perfeito. A minha questão é se é possível afirmar que o agente moral idealizado se justifica pelas consequências de suas atitudes, cuja sintonia com a felicidade da maioria seria condição necessária e suficiente para predicar a ação moral, prescindindo de qualquer outro critério capaz de justificar a desigualdade do valor moral do agente em certos contextos. Em geral, os utilitaristas assumem a vida ou o não atentado à vida (o sofrimento) como critério moral último, no entanto, eles homogeneízam a vida a tal ponto que inviabilizam o valor moral das açóes que estão em consonância com motivaçóes que atravessam as nossas escolhas de forma profundamente enraizada em nossos sentimentos. $\mathrm{O}$ agente 
moral utilitário deve agir, como costumava defender Mill, como indivíduo desinteressado e estritamente imparcial, cuja açáo deve levar em conta que a sua vida tem o mesmo valor que a dos demais agentes morais (MILL, Utilitarismo, Cap. II). O utilitarismo elide um fato importante, inscrito no reconhecimento de que os agentes morais podem ser valorados diferentemente em contextos em que o componente da empatia ganha uma particular relevância, como no exemplo que acabo de oferecer.

A confusão que o utilitarismo faz é entre a tese razoável de que nenhum agente moral detém a priori o monopólio sobre a escolha do outro ou que um agente não tem o direito de, por decisão do seu arbítrio, se diferenciar moralmente dos outros agentes, com a obrigação moral de tomar todos os agentes morais como instâncias cujo valor moral é absolutamente igual em qualquer contexto. Ou seja, o fato de que todos os agentes morais podem, em princípio, ter um valor moral igual (ninguém tem o direito de aniquilar arbitrariamente ninguém) não implica que, seja qual for o contexto ou a situação, os agentes morais sejam todos iguais, pois é perfeitamente possível e foi o que quis ressaltar com o meu exemplo - que um agente moral sacrifique a solução ótima proposta pelo cálculo racional em nome de uma motivação afetiva que não pode ser reprovada moralmente de forma tão fácil e está longe de ser um "desperdício".

Farei agora algumas consideraçóes críticas ao utilitarismo, por meio do recurso à radicalização de algumas de suas premissas. Mostrarei que as premissas do utilitarismo que se apoiam na experiência não são suficientes para a adoção do cálculo de utilidade como critério moral. Alguns estudos empíricos (como o que vou citar em seguida) revelam que a empatia desempenha um papel central na rejeição da atitude utilitária em alguns dilemas morais. Eles evidenciam uma grande dificuldade de pessoas sacrificarem alguém próximo a elas em nome de uma solução ótima que preserva uma maior quantidade de beneficiados. Dificilmente alguém empurraria, por exemplo, a mãe num trilho de trem para evitar que um trem fique desgovernado e tombe, matando cem pessoas. Um recente artigo publicado na Nature corrobora a tese da empatia

\footnotetext{
${ }^{6}$ Um sacrifício que não beneficia a maioria é um desperdício, segundo Mill. Nesse sentido, ainda que Mill reconheça que o sacrifício é uma atitude possível de ser empreendida pelos seres humanos, ele ressalta que, se ela não estiver em sintonia com o critério da utilidade, é um desperdício. Ele escreve: "A moralidade utilitarista reconhece nos seres humanos o poder de sacrificar o seu bem maior para o próprio bem dos outros. Ele só se recusa a admitir que o sacrifício é em si uma boa. Um sacrifício que não aumenta, ou tende a aumentar, a soma total de felicidade, que ela considera como desperdiçado" (MILL, Utilitarismo, Cap. II).
} 
como importante variável que veda a adoção do cálculo de utilidade como único critério para avaliação moral. Esse estudo demonstra que apenas pessoas que sofrem danos no córtex pré-frontal tomam, sem nenhuma hesitação, decisôes utilitárias que privilegiam a maioria em detrimento de qualquer relação empática que possamos guardar com alguém. ${ }^{7}$ Ora, essa é justamente a região do cérebro (junto com a amígdala) responsável pelas emoçôes. $\mathrm{Ou}$ seja, a motivação para decisões que tomam a atitude utilitária como o único critério para a avaliação moral é seriamente comprometida pelo componente empático que parece mostrar uma indisposição dos homens para as açôes em que o cálculo racional é o único critério válido. Uma pessoa não empurra a outra, sobretudo quando se trata de alguém com algum grau de proximidade, porque a quantidade de beneficiados não a move necessariamente a tomar uma decisão utilitária, independentemente do contexto em que ela esteja. A quantidade de beneficiados também não é suficiente para justificar moralmente a adoção do cálculo racional como critério de avaliação em qualquer contexto. De um ponto de vista da história evolutiva e da estrutura neurológica humana, há sérios indícios empíricos de que não podemos homogeneizar o agente moral desconsiderando o feixe de múltiplas emoçóes ou sentimentos (entre elas destaco a empatia) que compóem a tomada de decisóes morais. $\mathrm{O}$ estudo enfatiza que o cálculo utilitário só poderia ser um critério moral absoluto, caso tivéssemos sérios abalos em nosso sistema nervoso, os quais poderiam nos habilitar a prescindirmos das emoçôes ou sentimentos, como a empatia, nos nossos julgamentos morais. Nesse sentido, há uma resistência da experiência quanto à adoção do cálculo de utilidade como único critério moral.

Notem que não tenciono negar que, de um ponto de vista da definição de racionalidade como a otimização de recursos escassos, certas atitudes podem ser mais ou menos racionais. No entanto, isso náo significa que elas sejam mais ou menos morais, caso não se leve em consideração outras variáveis na atribuição dos predicados morais. Ainda que se aceite o critério da quantidade de beneficiados como tribunal para avaliaçáo da ação quanto à sua moralidade, isso não isenta o fato de que deva ser justificado e, preferencialmente, deva estar em sintonia com algumas de nossas intuições, especialmente aquelas ligadas às nossas relaçóes empáticas. Com essas consideraçóes, acho que é possível mostrar que a compreensão do agente moral do utilitarismo é bastante austera e se distancia de várias motivaçôes de nossas açôes que não são completamente redutíveis ao cálculo da utilidade, nem podem ser completamente anuladas na

${ }^{7}$ Ver: KOENIGS; YOUNG; ADOLPHS; TRANEL; CUSHMAN; HAUSER; DAMASIO, 2007 
avaliação de nossas açóes. O ônus que cabe ao utilitarismo é ter de provar que a ação racional implica ação moral. Isso não é evidente.

Esse problema, na minha exposição, se voltou para uma espécie de déficit antropológico do utilitarismo, o qual iguala os agentes morais de forma tâo radical que desconsidera a potencialização do valor de certos agentes em certos contextos. A minha ideia é de que a igualdade inicial do valor moral (ninguém tem a priori o direito de destruir ninguém) não pode elidir a potencialização do valor de certos agentes, quando se trata de uma decisão de se autossacrificar por uma razão de origem afetiva. O sacrifício em nome de outra pessoa sempre acarreta o aumento de valor no valor de um agente moral que está sendo salvo por aquele sacrifício. Tentei mostrar que o agente moral é mais complexo, de sorte que a aceitação da tese de que todos os agentes morais podem ter, num primeiro momento, o mesmo peso na decisão quanto a uma determinada atitude, que invariavelmente implica outras pessoas, não significa que eles sejam todos absolutamente iguais a posteriori, ao ponto de que as suas açóes tenham que visar apenas ao benefício de uma maioria quantitativamente determinada. Particularmente nos contextos em que náo se trata de atentar contra a vida de ninguém, mas de escolher salvar alguém, os agentes morais podem agir em função de uma alta dose de envolvimento emocional que está em desacordo com o cálculo de utilidade. Tenciono explicitar agora que os problemas do utilitarismo não repousam apenas na sua austera compreensão do agente moral como um átomo racional, mas que eles residem também numa desconsideração da dimensão social e contextual da ação moral.

\section{O DÉFICIT SOCIOLÓGICO DO UTILITARISMO}

Vou enfatizar agora o problema de se eleger a quantidade de beneficiados em detrimento de um critério que qualifique o benefício, no interior de um determinado contexto. Minha ideia é que o utilitarismo tem um déficit cultural importante relativo à falta de flexibilidade do critério de bem-estar ou felicidade. Os valores sofrem oscilaçóes que configuram diferentes redes de uso dos predicados morais, no transcorrer da história. É evidente que o utilitarista concede variaçôes históricas do que é correto moralmente, mas meu ponto é que essas variaçóes históricas precisam ser pensadas em função de um critério moral que promova essas mudanças, em sintonia com o contexto em que elas ocorrem, e que respeite as diferentes perspectivas que se encontram no interior desse contexto. Ou seja, não está dado numa sociedade o que ela entende por felicidade. 
Quanto ao reconhecimento de que os valores morais variam historicamente, Cláudio Costa oferece um exemplo: a mudança das lutas nas arenas dos circos romanos, que custavam as vidas de alguns para a alegria de vários, para as atuais lutas de boxe. Ele defende, com isso, que a sociedade pode corrigir distorçóes morais, como o circo romano, em sintonia com o refinamento do prazer que náo precisaria implicar a dor acompanhada de morte (COSTA, 2002, p. 169-170). No futuro, sociedades civilizadas não teriam, segundo aquele autor, lutas de boxe. Essas sociedades teriam outras formas de obter prazer que não passariam pelo sofrimento de alguns.

Vou me ater ao próprio exemplo oferecido por Cláudio Costa para mostrar algumas fragilidades do utilitarismo, quando pensamos em contextos culturais distintos. Primeiramente, gostaria de destacar que a uniformização da cultura, tanto romana, quanto atual, implícita no exemplo do referido autor, indica uma negligência recorrente dos utilitaristas quanto à natureza do bem no horizonte de uma cultura. Cláudio Costa aposta num desenvolvimento cultural - sem esclarecer muito bem o que isso significa - que terminaria por condenar moralmente as lutas de boxe e, por fim, extirpá-las, como ocorreu com o circo romano. Entretanto, dificilmente algumas sociedades ocidentais ou parte importante da população seriam hoje majoritariamente contra, como sugere Cláudio Costa (2002, p.169) o circo romano, se no lugar de gladiadores (escravos ou prisioneiros de guerra) tivéssemos estupradores e matadores em série de crianças. Meu contraexemplo não é uma forma velada de hierarquizar os agentes morais ou de julgar quem é mais ou menos importante socialmente. Ele consiste numa tentativa de sublinhar que, sem uma análise sociológica mais acurada, o utilitarismo se afasta dos valores das culturas vigentes, à medida que se compromete com valores morais injustificados socialmente ou para os quais ele não encontra uma justificativa assentida pelos membros da sociedade. Para que o exemplo do circo tenha validade, deve-se levar em conta quem é o "gladiador" submetido ao combate e qual é a sociedade em que o circo está inserido. Não é apenas um compromisso com o não sofrimento que garante que uma sociedade não adote estádios ou circos romanos nos quais as pessoas são dilaceradas por leóes.

O problema da argumentação utilitarista, especificamente a de Cláudio Costa, é que ela tem dificuldade em relação às diferentes compreensóes culturais do que é moralmente bom. O ponto não repousa na prerrogativa de que as pessoas têm mais ou menos prazer com o sofrimento alheio, mas significa investigar a instituiçáo dos valores morais nas diferentes culturas e 
pensar em que medida é possível ter um corpo homogêneo de valores numa determinada sociedade. Certamente, para se eleger o não sofrimento como um valor moral partilhável interculturalmente, é necessário uma justificativa mais clara, inclusive sobre o que significa sofrer. Novamente, é preciso qualificar mais o agente moral, para que os indivíduos de diferentes culturas possam se reconhecer nesse agente.

$\mathrm{O}$ argumento naturalista do apelo à nossa história evolutiva, que é evocado por alguns utilitaristas para lastrear uma posição transcultural, ainda não me parece suficiente para justificar, pelo menos hoje, a adoção do cálculo de utilidade como critério de avaliação da moralidade de uma ação. Mesmo que evitar o sofrimento e promover a otimizaçáo do prazer possam ter sido uma boa estratégia evolutiva, isso não implica dizer que esse par conceitual continue sendo um elemento decisivo para pensar a condição humana. Tudo indica que a conservação foi realizada por meio da planificação de nossas necessidades básicas que passam por evitar privaçóes que muitas vezes geram sofrimento. Contudo, ainda que o utilitarismo possa ter a seu favor a tese de que os homens, de um ponto de vista da sua história evolutiva, e em vários momentos, agiram em sintonia com critérios que evitam o sofrimento e promovem o bem-estar social ou a felicidade - a partir do mecanismo de recompensa para os que agem em sintonia com a maioria e punição para aqueles que fazem o contrário ${ }^{8}$-, ele não pode estender esse critério para toda a história e determinar de maneira fixa a própria noção de felicidade ou bem-estar. A validade do utilitarismo na história evolutiva não pode obliterar seu déficit sociológico face à cultura produzida pelos seres humanos, nos últimos milênios.

Por não ser um critério inscrito de maneira inequívoca na condição humana enquanto uma variável fundamental para a sua adaptação ao mundo enquanto espécie nos dias atuais, o critério do não sofrimento não está isento de uma justificativa moral, para que seja adotado numa hierarquia de valores.

Meu argumento consiste na ideia de que é muito pouco prudente pressupor uma evolução social uniforme que legitima a substituição das arenas dos circos romanos pelos ringues de boxe, sem antes discutir, no interior de uma cultura, com subculturas distintas, o que é moralmente bom. Obviamente, a diversidade de valores não significa a impossibilidade de um código moral, por assim dizer, universal ou mesmo que não sejam possíveis juízos objetivos em ética. Não se pode confundir o diagnóstico da

${ }^{8}$ Ver: JOHNSON, 2005; FEHR; GÄCHTER, 2002. 
diversidade de valores com a legitimação dessa diversidade ou mesmo com a inexorabilidade dessa diversidade. $\mathrm{O}$ ponto que tenciono sublinhar consiste no reconhecimento de que a diversidade cultural aponta para o fato de que a quantidade de beneficiados os quais podem, por assim dizer, evitar o sofrimento não é necessariamente um critério moral que poderia unificar per se a diversidade de opinióes humanas sobre a moralidade, em diferentes culturas. É preciso qualificar o benefício e os beneficiados. Isso, por sua vez, só pode ocorrer no contexto cultural. Se, por um lado, o relativismo cultural pode incorrer em contradições relevantes - ver, por exemplo, as críticas de Williams (2005) -, o utilitarismo pode oferecer uma concepção moral pouco abrangente, por subestimar a diferença cultural entre as sociedades, que se dilata ao longo da história.

As relaçôes interculturais não são, a priori, movidas por um único ponto de vista que é capaz de orquestrar interesses diversos em torno de uma mesma sinfonia. Se a busca pelo não sofrimento fosse um bem moral constante e transcultural, não teríamos códigos morais diferentes, em alguns casos antagônicos. A diversidade cultural está presente em cada decisão do agente moral e atravessa a sua pessoa como marca de sua individualidade. Por isso, não se pode elidir tão facilmente os conflitos interculturais em favor da escolha do cálculo de utilidade como critério moral que privilegia o não sofrimento. A aceitação do referido cálculo já implica a compreensão moral de que ele é a melhor forma de resolver conflitos culturais, no entanto, isso só pode ser estabelecido a posteriori, quando, de algum modo, os envolvidos no conflito se disponham a recorrer a uma solução que otimize o bem-estar ou felicidade da maioria e que tenha clareza social sobre o uso desses conceitos. O ponto é que, para chegar a essa resolução, os indivíduos já devem estar movidos por alguma prerrogativa moral que justifica a disposição para resolver o conflito de acordo com o cálculo de utilidade, visto que o simples cálculo não se configura como uma justificativa. Portanto, é preciso antes decidir pela resolução do conflito para, em seguida, se recorrer ao cálculo, mas isso só é possível, quando a sociedade tiver uma noção uniforme do que é a felicidade.

Sem partir de um acordo entre os membros de diferentes culturas, o utilitarismo tem o ônus de justificar seu critério independentemente da cultura à qual ele será aplicado. Se o cálculo de utilidade não se apoia no reconhecimento da diversidade cultural, ele termina enredado num círculo vicioso, quando visa à fundamentação da moral. Para provar que o recurso ao cálculo de utilidade é um bem moral relevante, independente da cultura, o 
utilitarismo pressupóe que os agentes morais estáo dispostos a serem racionais (imparciais) e realizarem cálculos de utilidade. Contudo, os utilitaristas precisam provar que os agentes morais estão dispostos a serem racionais.

O raciocínio utilitarista parece se apresentar da seguinte maneira: por que o sujeito é racional (deseja otimizar o bem-estar), ele deve agir racionalmente (calculando a maximização do bem-estar), e deve agir racionalmente (otimiza o bem estar), porque é racional (deseja maximizar o bem-estar). Para fugir a essa circularidade, o utilitarista precisa justificar moralmente que o cálculo racional é a melhor forma de resolver problemas morais que envolvem diferentes culturas. Para fazer isso, porém, ele precisa explicar o critério por meio do qual ele elegeu o cálculo racional como norte da ação moral e não pressupor que os agentes morais são racionais e agem racionalmente, porque são desterrados e absolutamente indiferentes ao contexto cultural no qual constroem e estipulam os seus valores.

Para os utilitaristas, os indivíduos devem agir em conformidade com o bem-estar por meio do recurso ao cálculo de utilidade. Todavia, por que aceitar um prognóstico (a normatividade do cálculo utilitário) cujo diagnóstico (a aposta de que os agentes morais são racionais) não reflete uma análise da diferença cultural que marca a produção de valores morais? Ou seja, por que os agentes morais deveriam abandonar os seus critérios de bem-estar ou felicidade, em nome de um critério, materializado num contrato, que preza pela quantidade de beneficiados no que concerne ao não sofrimento? Ora, isso só poderia ser exigido, se os indivíduos se reconhecem independentemente da cultura naquele critério. Entretanto, o utilitarismo não pode ser um horizonte para balizar conflitos culturais com alternativas morais relevantes, se ele, em última análise, não reconhece os conflitos culturais como um problema moral. Para isso, é necessário antes, por um lado, a procura pela legitimação de critérios de avaliação moral interculturais, que permitam discursar sobre "evolução" social e, por outro, a caracterização pela contextualização histórica e cultural dos benefícios partilhados intersubjetivamente.

É preciso procurar nas culturas critérios intersubjetivos e não tentar eliminar as diferenças culturais, apelando para um critério supostamente supracultural, o qual pode oscilar entre um etnocentrismo recalcitrante e um sistema moral inócuo, porque incapaz de dirimir conflitos culturais, visto que não reconhece a diferença entre as culturas. Se todos estivessem de acordo quanto ao cálculo da utilidade, não precisaríamos de nenhum critério moral, de sorte que o utilitarismo seria um truísmo. Todavia, a divergência sobre 
como qualificar o bem-estar ou a felicidade é que exige uma discussão da moralidade, para que os agentes morais possam estabelecer um critério para a validação de sua ação que não seja apenas restrito ao grupo cultural ao qual eles pertencem.

O utilitarismo tem o ônus, portanto, de harmonizar seu critério de avaliação dos juízos morais com a motivaçáo humana para a ação moral, que nem sempre é a mesma em toda cultura, nem muito menos em todos os indivíduos. Se ficar no patamar da quantificação do benefício pautada na variável não sofrimento, ele será obrigado a esvaziar o agente moral de seus valores culturais e emotivos, deixando um sujeito tão abstrato quanto desumano.

ANDRADE, Érico.The empty man: a critique of utilitarianism. Trans/Form/Ação, Marília, v. 36, n. 2, p. 105-122, Maio/Ago., 2013.

\begin{abstract}
This article criticizes the utilitarian understanding of the moral agent as a rational atom invariably willing to act in accord with non-suffering. My hypothesis is that utilitarianism drains human beings of their motivations in order to offer an opaque view of the moral agent. Utilitarianism is therefore incapable of solving moral dilemmas that involve, on one hand, self-sacrifice for affective reasons and, on the other hand, conflicts where distinct cultures oppose each other. The point here is that it is not necessarily immoral for an agent to sacrifice an optimal solution (as proposed by the majority-favoring utilitarian calculation) in favor of an affective motivation which judges that one life may be worth more than another. Furthermore, suffering is not necessarily immoral in the same way in all cultures.
\end{abstract}

KEYWORDS: Moral, Utilitarianism, Good, Context, Empathy.

\title{
REFERÊNCIAS
}

BENTHAM. J. An introduction to the principle of morals and legislation, 1823. Disponivel em: http://www.econlib.org/library/Bentham/bnthPML0.html. Acesso em: 26/07/2012.

COSTA, C. Razóes para o utilitarismo.Ethic@. Florianópolis: UFSC, v.1, n. 2, p. 155-174, 2002.

DALL'AGNOL, D. Utilitarismo kantiano? UFSC (pré-publicações), Ano IV, n. 49, 2001. 
DIAS, M. C. M. A ampliação do espaço moral no utilitarismo de John Stuart Mill: uma comparação com a moral do utilitarismo de Bentham. 2011. Tese (Doutorado em Filosofia) - Faculdade de Filosofia, Letras e Ciências Humanas, Universidade de São Paulo, São Paulo, 2011.

FEHR, E. and GACHTER, S. Altruistic punishment in humans. In: Nature, $\mathrm{n}^{\circ} .415$, 2002: 137-140.

HARE, R. Ética: problemas e propostas. Trad. M. Mascherpe e C. A. Rapucci. São Paulo: Unesp, 1998 (1997).

JOHNSON, D. P. God's punishment and public goods: A test of the supernatural punishment hypothesis in 186 world cultures. In: Human Nature, 16, 2005, 410-446.

KOENIGS, M.; YOUNG, L.; ADOLPHS, R.; TRANEL, D.; CUSHMAN, F.; HAUSER, M.; DAMASIO, A. Damage to the prefrontal cortex increases utilitarian moral judgments. Nature (DOI: 10.1038/nature05631). v. 446, April, 2007.

MILL, S. J. Sobre a liberdade. Trad. Ari Brito. São Paulo: Hedra, 2008.

MILL, S. J. Utilitarianism, 1863. Disponível em: http://www.utilitarianism.com/mill1. htm. Acesso em: 27/06/2012.

SIMÓES, MV. Rule-utilitarianism. Etic@, Florianópolis: UFSC, v. 8, n. 3, p. 47-62, 2009.

SINGER, P. Ética Prática. Trad. J. L. Camargo. São Paulo: Martins Fontes, 2009.

SMART, J. J. Extreme and restricted utilitarianism. The Philosophical Quarterly, v. 6, n. 25, p. 344-354, 1956.

SMART, J. J. C. Utilitarianism and Justice. Journal of Chinese Philosophy, 1978.

WILLIAMS, B. Moral: uma introdução à ética. Trad. R. Mannarino. São Paulo: Martins Fontes, 2005.

Recebido em: 04.09.2012

Aceito em: 26.11.2012 
ANDRADE, É. 